\title{
The Non-Lethal Technologies Against the Terrorism
}

\author{
Adelina D. Tumbarska
}

\begin{abstract}
The fight against contemporary terrorism involves variety of situations in which terrorists are mixed with or are in immediate vicinity to the citizens. Use of conventional weapons in such environment often results in high levels of unintended casualties and destruction. Non-lethal technologies, having reversible effects on people, equipment and infrastructure, can significantly contribute to prevention and countering terrorist actions while minimizing collateral damage. The article is an attempt to present in a synthesized brief form the results of a several-years study on the current and potential applications of non-lethal means in the terrorist threats defense and counteraction. The capabilities of both non-lethal weapons used for decades as well as some modern solutions and emerging technologies for protection of infrastructural sites and valuable assets and in counterterrorism operations have been considered.
\end{abstract}

Index Terms - Non-lethal technologies; Non-lethal weapons (NLWs); Terrorism; Counter-terrorism; Infrastructure protection.

\section{INTRODUCTION}

The respect to human life is increasingly established as a fundamental value in the modern societies. At the same time, terrorist activity shows a tendency to cause maximum human casualties and damage, with attacks typically taking place in densely populated areas and targeting civilians and civil infrastructure. The aim of terrorists is not only to kill and destroy, but "to spread fear, anxiety and panic, creating the perception that every citizen and critical node in a country's infrastructure is vulnerable to attack" [1].

Many scientists, analysts and politicians point out that terrorism has gained a new identity since the mid-1990s. Formerly, terrorism has been confined to a particular country or region and has included an escape route for the offenders, in many cases the target has been infrastructure and the population has been warned for avoiding casualties. Now "this has been transformed by the move away from small secretive terrorist groups to a global and relatively large-scale terrorist organization attacking symbolic soft targets, infrastructure and the committing of mass murder by extremists that are prepared to die for their cause" [2]. Concept of 'new terrorism' has been created to describe the new features of terrorism which include different actors, motivations, goals, tactics and actions compared to the old concept [3]. According to it, the terrorists have become more lethal and seek to use maximum force to cause a larger number of casualties. "New terrorism is more violent. Under

Published on May 23, 2018

Dr. Eng. Adelina Tumbarska is an Assistant-Professor at the Department "Technologies and Systems for Protection" of the Institute of Metal Science, Equipment and Technologies with Hydro- and Aerodynamics Center" Acad. A. Balevski" at the Bulgarian Academy of Sciences (IMSETHAC - BAS), Sofia, Bulgaria; E-mail: y.toumbarski@ims.bas.bg. the old paradigm, terrorists wanted attention, not mass casualties. Now they want both" [4]. The 9/11 attack on the World trade center is the most dramatic example of the new terrorism, and unfortunately, according to experts, evidences exist that it is not a single act but an evolving pattern that points to growth of new asymmetric threats [2].

Globally, the terrorism goes beyond borders and continues to become more complex, more indiscriminate and more deadly [5]. It is already being used not only as a tool to achieve specific political goals in a particular country or region but is targeted to the existing system of international relations. "It aims at creating chaos and economic destabilization of targeted countries and causing fear and psychosis among the population. The ultimate goal is to provoke a global crisis and change the existing world order" [6]. Since the stability and security are key factors for the economic prosperity, the new terrorist threats affect each country, directly or indirectly. Although the pessimistic predictions about a global recession following 11 September 2001 did not come true, the economic losses to both USA and world economy were considerable. "Given the negative effects of terrorism on developed countries, most countries may prove more vulnerable to this type of threat, given that developing economies are more susceptible to terrorism and its impact on global economy due to increased reliance on foreign trade, foreign investment combined with a lower degree of diversification of production, capital markets vulnerable and with pre-existing internal problems" [7].

Countering contemporary terrorist threats involves variety of actions in close proximity to citizens. In many situations terrorists are mixed with the population that serves them as a human shield. Avoiding collateral damages requires application of unconventional methods and means, since the use of conventional weapons in such environment often results in high levels of civilian casualties and destruction. Non-lethal weapons (NLWs) ${ }^{1}$, having reversible effects to people, equipment and infrastructure, can be successfully applied within the whole spectrum of measures for preventing and countering terrorist threats, while preserving human life and property.

The terrorist acts of 11 September 2001 led to awareness of the real threats of terrorism, resulting in the adoption of international documents such as the European Security Strategy, which marked a turning point in the development of the European Union's security policy. In 2004, the NATO Anti-Terrorism Program was launched. The need of reliable protection against the growing number of terrorist attacks on government, military, industrial and other sites has also led

${ }^{1}$ Non-lethal weapons are defined by the US DoD as "weapons, devices, and munitions that are explicitly designed and primarily employed to incapacitate targeted personnel or materiel immediately, while minimizing fatalities, permanent injury to personnel, and undesired damage to property in the target area or environment. Non-lethal weapons are intended to have reversible effects on personnel and materiel". 
to introducing rigorous measures and standards to increase the effectiveness of critical infrastructure security systems in the United States and a number of European countries.

\section{NON-LETHAL TECHNOLOGIES IN THE CRITICAL INFRASTRUCTURE PROTECTION}

Critical infrastructure protection became a priority issue for the countries in response to the increasing risks posed by terrorism. The physical protection of critical infrastructure is intended to "harden" the target, making it more difficult to be attacked by terrorists. Since the terrorists adapt their behavior to the security landscape changes, the "target hardening against terrorist attacks ideally should be flexible and dynamic, rather than attempt to build walls around selected targets" [1].

The following components must be present in any effective physical protection system to the degree necessary to meet the expected threat: entry control, intrusion detection, delay of the intruder, and response to an offensive action. These functions must be performed in a sequence and within a period of time that is less than time required for the adversary (terrorist) to overcome the physical protection system and commit the act (e.g. property destruction, kidnaping and hostage taking, personal injury, murder, etc. [8]. Modern systems for infrastructure objects protection are based on the so-called "zone" or "layer" strategy. Generally, a system for protection consists of several different but complementary layers of protection which must be equipped so that each of them should help detect, slow down and deter penetration. The level of protection of a building or area is usually determined by the level of risk of penetration or other threats to security of the protected object. Such concept requires the availability of resources to detect the presence of a potential threat on land, air, water or underwater, depending on the object location. It should be noted that while the land and sea surface threats are wellstudied, underwater and air threats are rapidly evolving as a result of technological advances and increased access to diving equipment, small submarines and unmanned craft and aircraft. Essential part of these systems is the surveillance which should provide an early detection and warning - crucial for the timely and adequate response to an attack. In the protection systems, within the different protection layers, it is imperative to use non-lethal options, as the violation may be unintentional and the response time may be insufficient to determine the nature of the threat and the participants involved.

\section{A. Protection of infrastructure objects located on land}

Generally, the perimeter of an object comprises the restricted zone, the object/property borders, and a band beyond the borders, including the airspace above the entire object. The perimeter can provisionally be divided into three zones with different levels of risk: surveillance zone, warning zone and restricted zone. The outer one is intended to monitor for approaching potential intruders (people or vehicles), detect intrusion and alert the staff about the threat, through radar systems, sensors operating on different physical principles, video-cameras and other means for detection. The objects boundaries are usually outlined by various types of fences (including electrified, with barbed or razor wire, cutting elements, spikes, etc.) equipped with sensors that detect attempts to cut or climb the fence, or deter intrusion attempts, barriers, mechanical obstacles, lights and other means to indicate the perimeter. In case of penetration into the perimeter, audible or visual signals are used to warn the intruder, while the personnel is assessing his intentions and considering tactics to delay or prevent potential attack through non-lethal means. Most commonly applied non-lethal means in the warning zone are sirens and other acoustic devices; flashing lights, spotlights, low energy lasers and more. Entering into the protected zone requires the use of means to combat the threat - non-lethal or lethal. Selected non-lethal options must be effective within the time interval to allow capturing the offender or the subsequent use of lethal means as last resort. Non-lethal weapons used in the protected area include car stoppers (various stationary or rapidly deployed obstacles, tire spikes, wheel entanglement systems, electromagnetic pulse devices to stop engine operation, etc.); electro-shock devices; dazzling lasers; non-lethal munitions such as: modular crowd control munitions, rubber bullets, munitions or hand grenades with rubber/plastic balls, chemical agents (tear gas, pepper spray), flash-bang or other combinations of effects, etc. Modern, but not yet widely available, solutions such as acoustic devices (e.g. Long Range Acoustic Device, LRAD - originally developed to create security zones around ships, currently used by various forces, as well as in infrastructure protection) and directed-energy weapons (DEWs), including active denial systems and various types of lasers, can be effectively used in such systems.

\section{B. Protection of harbors, ships and other marine assets}

The safe and continuous operation of harbors and ports is crucial for the global economy; thus it is essential that marine assets are as secure as possible. A suicide terrorist attack by explosive-laden boat against the US guidedmissile destroyer "Cole" in the port of Yemen in 2000 killed 17 sailors. Another attack by "boat-bomb" against the oil tanker "Limburg" in the Gulf of Aden in 2002 led to shorttime collapse of the international shipping in the region and its cost to Yemen is estimated to $\$ 3.8$ million losses a month in port revenues. The heaviest attack on a passenger ship so far is this to "Superferry 14" in the Philippines in 2004, when a TNT-bomb placed on board caused 110 fatalities. "Globally, terrorists have shown an increasing interest in using small boats to attack military and commercial shipping and maritime facilities. The tactics and techniques of using commercial or non-commercial vessels (under 500 tons) or swimmers to emplace or deliver improvised explosive devices have proven effective and exportable" [9]. A number of other terrorist acts, using various means of attacks, against coastal infrastructure and ships have been registered since 2000. This caused reconsidering the vulnerability of merchant and warships, naval bases, commercial ports, oil platforms and terminals and other coastal facilities, and strengthening measures for their protection.

Harbors and ports are more vulnerable to terrorist attacks than other areas because of their dimensions, general accessibility from water and land, intense traffic of materials 
and people, their location in populated areas, the density of transport ways (roads, railways, navigation channels), and the concentration of passengers, merchandise, properties and business in harbor areas, which represent multiple potential targets of the terrorists [10]. Integrated port protection systems, using multi-layer approach, must provide deterrence, detection, assessment, delay and counteraction in case of unauthorized access attempts in regard to harbor perimeter and port facilities used by port operators. The concept of perimeter protection from the land-side, as well as the means used to monitor, alert and respond to a threat, are similar to that of the land located objects. The water-side part of the system requires the use of radars, sonars, sensors and other surveillance equipment to detect and identify potential threats on the sea surface and underwater. Nonlethal means for warning such as lasers or powerful search lights to illuminate intruders, acoustic hailing devices, pyrotechnics, etc., are effectively used to discourage approaching vessels and swimmers. Widely used means to prevent the access are various types of barriers deployed on surface and underwater which are considered one of the most reliable defense options especially against fast boat attack [11]. Recently, modern unmanned robotic systems for port and coastal protection, which are capable to detect, track and interdict potential air, sea and undersea threats like hostile UAVs, UUVs, terrorist fast boats or divers, have been developed.

Protection of ships in ports, at anchor and at sea is also based on defining a perimeter and establishing security zones, applying means for detection, identification and warning similar to these used in port protection. Modern means for detection are robots for underwater inspection of large vessels hulls [12] which are designed to find explosive devices attached to the ship.

Military ships at civilian ports are more vulnerable to attacks than on high seas or in naval bases. The biggest challenge in such environment is recognizing threats among the many neutral civil craft. "The chances of detecting and countering a terrorist boat vary widely depending on several factors, including early identification of the attack and weapons available" [13]. Moreover, because of the limited area, the protective zones are significantly narrowed, which additionally reduces the time for warning the intruder and response to the threat. This requires the use of one or more patrol boats in the restricted area adjacent to the ship. The non-lethal protection equipment includes rapidly deployed barriers and nets against vessels (including nets deployed from helicopters) and swimmers, rope-nets for entangling the boat propellers shot by pneumatic launchers, electromagnetic pulse devices for stopping the boat engine, water cannon, water curtains, flash-bang and kinetic nonlethal munitions, underwater acoustic hailing devices, underwater pneumatic devices, anti-swimmer grenades, etc.

Military ships when pass through narrow channels or operate in coastal areas are at risk of attacks from hostile crowds on shore, suicide vessels and terrorists on land, in water or in the air. "Base security requires capabilities for crowd control, individual incapacitation, area and access denial, and the ability to clear facilities. In all of these diverse environments, threats can be ambiguous and involvement of non-combatants possible" [14]. Among the other non-lethal weapons, in such situations are recommended for use chemical agents (applied in accordance to the Chemical Weapons Convention); highpower microwave for stopping vehicles or vessels, solidstate lasers for advanced non-lethal weapons applications, unmanned or remotely controlled platforms for non-lethal weapons applications [14].

Civilian vessels are subject of not only terrorist but also of pirate attacks ${ }^{2}$. Pirate attacks are usually carried out by at least two high-speed boats approaching the ship from different sides, with pirates armed with automatic weapons and grenade launchers. While cruise ships are difficult to board because of the high freeboard and relatively high speed of sailing, merchant vessels, especially heavily loaded cargo ships, are easy to take if the pirates are able to get close enough. National laws of many countries do not allow crew on their ships to carry firearms. Also, many countries have laws prohibiting the import of any firearms into their territory. An effective, but rather controversial measure (because of its potential to escalate the violence), is the hiring of armed guards on board. However, it is expensive and related to legal and bureaucratic problems. For these reasons, the technology currently used for protection of ships against this type of threat relies on non-lethal devices to keep the attackers at a distance and prevent boarding, without invoking an armed response [15]-[17]. Early detection of the potential threat in the outer zone of the perimeter (in the order of dozens of kilometers) is essential to enable detection of the threat, decision-making and implementation of the necessary measures. At the beginning of an attack, the use of the LRAD, also called "sound cannon", is particularly effective - the use of such device has averted a pirate attack on the cruise ship "Seaborn Spirit" in 2005. Besides the non-lethal means used to protect ships in other situations, for defense against pirate attacks additional measures must be applied to prevent boarding: razor wire, boat traps (wires or nets to entangle the pirate boat propeller), electrified fences, anti-intrusion barriers to prevent climbing, water curtains, non-lethal munitions with flash-bang, sting-ball and other effects, launched by pneumatic devices or hand thrown, etc. In case of successful boarding, measures to prevent taking the ship include using sticky or slippery substances to hinder the movement on the deck, chemicals, smoke, pepper-spray, electro-shock devices, obstacles to avoid breach of doors, entry barriers with sound/light/smoke effect, ballistic protection of windows, grids for protection of vulnerable points against RPGs, etc.

\section{NON-LETHAL TECHNOLOGIES IN COUNTERING TERRORIST ATTACKS}

Non-lethal weapons can be used to prevent terrorist attacks even in the phase of their preparation. Often, terrorists choose place where to plan the operation and collect equipment (explosives, weapons) in a residential area near the site of attack. Neutralizing terrorists at this stage

2 Although terrorism and piracy are considered as distinct phenomena, based on different motivations and tactics, some experts see relationship between them, believing that part of the funds provided by the pirates is used to finance terrorist groups. 
prevents any attack, however, if the counter-terrorist operation is not properly implemented, the risk of collateral damage is significant due to the presence of explosives and weapons. "An assault team armed with calmatives to incapacitate, hi-frequency transmitters to disorient, and a combination of Tasers, rubber bullets and other non-lethal assault weapons systems could effectively neutralize the terrorist without endangering noncombatants in the immediate area" [18].

The problem of mixing terrorists with civilians, whether they are hostages or passers-by, increases the complexity of a proactive response, and counterterrorist operations often result in casualties. Flash-bang grenades, which cause shortterm blindness, deafness and shock, as well as other disorienting non-lethal munitions, provide the tactical team with a few seconds to take control over the situation and allow terrorists to be captured alive. Kinetic effect munitions, acoustic systems, electro-shock devices, generators and grenades for creating smoke clouds, are also used. In hostage situations, some calmatives that quickly cause incapacitation and allow for capturing terrorists and rescuing hostages are extremely effective. However, development and application of incapacitating agents is severely limited by international law and poses significant risks to fatal consequences due to the small difference between their effective and lethal doses, heavily dependent on the individual's physiology. The most significant incident in the short history of NLWs was caused by such substance (supposed fentanyl) introduced into the building's ventilation system in a hostage rescue action in Moscow in 2002. As a result of the operation, all the 40-50 heavily armed Chechen terrorists were neutralized and killed, disposed bombs - disarmed, and 129 of the 916 hostages have lost their lives. The world's public reactions to this accident are controversial - most of them criticize the actions of Russian Special forces, while others consider the operation to be successful, because the number of hostages saved significantly exceeds the number of casualties and because a direct storming of the theater would have killed much more people. It is subsequently proven that the majority of victims have not directly died from the chemical applied, but in result of poor organization during evacuation from the building, transportation and following inadequate medical care. Since fentanyl and other existing incapacitating agents are too powerful and potentially lethal, substances more suitable for tactical use probably will be developed. Other technologies that significantly increase the probability for saving hostages are directed energy NLWs active deterrent systems, lasers, pulse energy devices, as well as acoustic systems, communications blocking systems, anti-materiel agents for equipment damage, and more.

Preventing suicide attacks is one of the most complex situations in the fight against terrorism. In such cases, nets or sticky foam can be used to capture individuals. Various obstacles, spike strips, wire or carbon fiber wheel entanglements and mobile devices to stop the engine operation by electromagnetic impulse are effective for arresting "car-bombs". Chemical agents for crowd control (tear gas, pepper spray) and malodorants (malodorous substances) are usable in "cleaning" buildings, forcing terrorists to leave their shelter and facilitating further actions to capture them. After September 11, interest in anti-terrorist tools like electro-shock guns, slippery foam, aerosol sedatives, arresting nets, acoustic systems, dazzling lights, etc., has been demonstrated by civil aviation companies.

In addition to providing an intermediate option in the force continuum, the capabilities of non-lethal weapons provide several advantages over conventional weapons in countering terrorism: A disabled terrorist can be arrested and used as a source of information; The captured terrorist can't become a martyr for his cause; Forces attacking terrorists may be more aggressive and even if a civilian person is affected, the consequences for him will be temporary; In an unstable situation, the forces will be able to incapacitate all persons in a site, and then will be able to correctly identify and distinguish terrorists from others, i.e. it will not be necessary to make an immediate decision "life or death"; The lack of victims immediately reduces the socalled "CNN effect" related to the rapid spread of photos and storytelling about the event. "Indeed, non-lethal weapons allow the forces to directly influence the critical points of the terrorist schedule by stopping the terrorist narrative that is crucial to their operations" [19].

Newly developed non-lethal technologies allow for a more aggressive strategy against terrorism, regardless of the location or type of the incident. The temporary effects of the NLWs drastically lower the probability of death and injuries in counterterrorist actions related to the presence of civilians. Despite the fact that $100 \%$ risk-free use of NLWs cannot be guaranteed, technological advances combined with their skillful use and additional measures (such as the provision of antidotes, presence of medical personnel on the site, etc.) make them viable option in the fight against terrorism.

The strongly political nature of the war on terror and operational reality suggests that non-lethal weapons can be of particular benefit. Analyzing the NLWs capabilities to fight terrorism, [20] concludes that both the positive and negative potentials of these weapons seem to be increased when applied to counterterrorism operations, and ultimately "the advantages nonlethal weapons offer at the strategic level seem to outweigh the negatives and make them a particularly valuable tool for the war against terrorism".

\section{EMERGING NON-LETHAL TECHNOLOGIES AGAINST TERRORISM}

The fact that terrorists acquire more and more modern weapons gives a boost to even more intensive research into new non-lethal counter terrorism technologies. A number of countries have their own R\&D programs and centers for development of non-lethal weapons with various applications, including in the fight against terrorism. At international level several research projects on non-lethal technologies are coordinated and promoted by NATO and European organizations.

The Joint Non-Lethal Weapons Directorate (JNLWD) at the US Department of Defense is the leading organization in the world in the field of NLWs development. Currently, within the variety of NLWs with increased range and effects, the following devices with potential application in the fight against terrorism are under development and 
testing: Long Range Ocular Interruption (LROI) with an effective range up to $3000 \mathrm{~m}$ for protection of vessels, entry control points, checkpoints, convoys, and maritime ports and security zones; Mission Payload Module Non-Lethal Weapon System (MPM NLWS) and XM7 Spider NonLethal Launcher - vehicle, vessel or ground mounted tube launchers delivering non-lethal (flash-bang and sting-ball) munitions between $25-500 \mathrm{~m}$ for crowd control, convoy protection and maritime security; Mini-Distributed Sound and Light Array intended to hail, warn and deter individuals and vehicle operators from approaching entry control points, mobile patrols/convoys and vehicle checkpoints; Indirect Fire Munition (IDFM) for existing $81 \mathrm{~mm}$ mortar with a novel pyrotechnic payload; Multi-Bang Diversionary Grenade for the Special Operation Forces; etc. [21].

Developing non-lethal capabilities is one of the main directions in the NATO Defense against Terrorism Program. Various non-lethal technologies are being explored to enhance the protection of forces, infrastructure, aircraft, harbors and ports. For example, sensor nets, electro-optical detectors, rapid-reaction capabilities, unmanned underwater vehicles, magnetic barrier to complement sonar systems in detecting underwater threats, etc., have been developed within the sub-program on port/harbor protection [22].

Anti-materiel applications of the directed-energy technologies are being explored in some countries to create effective systems for disabling, damaging or destroying the enemy's equipment or capabilities. Considering the increasing access of terrorists to missile weapons, precision missile strikes could represent an enduring threat from both terrorists and rogue states. To address this threat, directedenergy systems for counteracting small-range missiles are under development which could be a valuable part of the critical infrastructure protection. "They could protect highrisk structures, such as major government buildings, major transportation nodes, vital commercial assets, power plants, and airports" [23]. DEWs are usable for defense of naval and air assets against rockets, artillery, mortars as well as against attacks by small boats and UAVs [24]. Directedenergy systems could be deployed at airports to defend planes from attacks by shoulder-fired missiles during takeoff and landing - the time when aircraft are most vulnerable. Ground-based lasers are being designed in Israel to protect population centers from terrorist attacks with Katyusha rockets and other improvised rocket, artillery, and mortar systems [23].

\section{CONCLUSIONS}

Non-lethal technologies provide more flexibility and additional opportunities to fight terrorism, especially in situations involving an increased risk of incidental damage. They can be effectively applied not only in defense mode in infrastructure protection systems, but also in most types of counter-terrorism operations. Appropriately selected and skillfully used non-lethal means can be extremely useful to neutralize a range of terrorist threats, enabling terrorists to be distinguished from civilians and increasing the probability of saving hostages and capturing terrorists alive. At the same time, the use of non-lethal weapons significantly reduces the risk of causing unintended injuries and innocent victims.

"Terrorism can only be ended at the political level, but it can be minimized and deterred through direct action" [17]. The continuous improvement of existing non-lethal weapons and the development of new promising non-lethal technologies can significantly contribute to taking a more active and resolute response to modern terrorist threats.

\section{REFERENCES}

[1] Physical protection of Critical Infrastructure Against Terrorist Attacks, Report of UN Security Council, Counter-Terrorism Executive Directorate, March 2017.

[2] C. Skinner, S. Cochrane, M. Field, and R. Johnston, "Defence Against Terrorism: The Evolution of Military Surveillance Systems into Effective Counter Terrorism Systems Suitable for Use in Combined Military Civil Environments. Dream or Reality?", NATO report RTOMP-SCI-158, UK, 2004.

[3] A. Spencer, "Questioning the Concept of "New Terrorism"', Peace Conflict \& Development, Issue 8, pp 1-33, 2006.

[4] R. Howard, and R. Sawyer. Terrorism and Counter-terrorist: Understanding the New Security Environment. USA: McGraw-Hill/ Dushkin, 2004.

[5] NATO's Defence Against Terrorism Program, Available: https:// www.nato.int/nato_static_fl2014/assets/pdf/pdf_2014_10/ 20151029_ 141007-dat-prog.pdf

[6] V. Nikolova, Special Means for Individual Protection: Means for Individual Protection in Sites of Critical Infrastructure, in AntiTerrorist Activities and in Operations in Crisis Response, BG: IMSETHAC-BAS, 2014

[7] I.G. Radulescu, "Terrorism and its Impact on Global Economy", Economic Insights - Trends and Challenges, vol. V (LXVIII), No 2, pp 87-94, 2016.

[8] Technology Against Terrorism: Structuring Security, US Congress, Office of Technology Assessment, 1992, Available: https://digital library. unt.edu/ark:/67531/metadc40029/m2/1/high_res_d/9235.pdf

[9] J. Carafano, "Small Boats, Big Worries: Thwarting Terrorist Attacks from the Sea", The Heritage Foundation, June 2007, Available: https://www.heritage.org/homeland-security/report/small-boats-bigworries-thwar-ting-terrorist-attacks-the-sea

[10] O. Radu, G. Slamnoiu, and L. Zarnescu. "Harbor Protection against Terrorist Threats: Difficulties and Possible Solutions", NATO Technical Report RTO-MP-SCI-180, 2006.

[11] K. Stoichev, A. Popov, and N. Lichkov. Technologies and systems for combating terrorism, BG: IMSETHAC-BAS, 2012.

[12] S. Vodenicharov, D. Bratanov, R. Michailova, K. Stoychev, and V. Najdenov. "Underwater Hull Observation system ARMUS". Proc. 15th International Scientific Congress "Machines, Technologies, Materials", pp 319-322, Bulgaria, 2017.

[13] R. I. Sikandar, "Analysis of Protection Measures for Naval Vessels Berthed at Harbor against Terrorist Attacks", Naval Postgraduate School, Monterey, USA, 2016.

[14] An Assessment of Non-Lethal Weapons Science and Technology, Naval Studies Board, Executive summary, Washington, D.C.: National Academies Press, 2004.

[15] M. Annati, "The Role of Non-Lethal Weapons in Maritime Operations", Maritime Interdiction Operations Journal, issue 9, pp 38-41, 2014.

[16] J. Alexander, "Piracy: The Best Business Model Available", JSOU Report 13-7, USA, 2013, Available: http://www.dtic.mil/dtic/tr/ fulltext/ u2/a591812.pdf

[17] C. Brewer, "Maritime Security \& Counter-Piracy: Strategic Adaptations and Technological Options", Journal of Energy Security, April 2009, Available: http://www.ensec.org/index.php?option=com content \&view=article\&id=188: maritime-security-aamp...

[18] Studies Combined: Cyber Warfare in Cyberspace - National Defense, Workforce and Legal Issues, USA: J. F. Jones, January 2018.

[19] S. Sonsalla, "Non-Lethal Weapons: The Key to a More Aggressive Strategy to Combat Terrorism", Technical Report, Air War College, USA, 2017.

[20] E. Nutley, "Non-Lethal Weapons: Setting our Phasers on Stun? Potential Strategic Blessings and Curses of Non-Lethal Weapons on the Battlefield", Center for Strategy and Technology, Air War College, USA, August 2003.

[21] DoD Non-Lethal Capabilities: Enhancing Readiness for Crisis Response - JNLWD Annual Review 2015, USA, Available: http:// 
jnlwp.defense.gov/Portals/50/Documents/Press_Room/Annual Reviews_Reports/2015/...

[22] Defence Against Terrorism Programme of Work (DAT POW). NATO

16 December 2015, Available: https://www.nato.int/cps/ic/natohq/ topics.htm

[23] J. Spencer, and J. Carafano, "The Use of Directed-Energy Weapons to Protect Critical Infrastructure", The Heritage Foundation, USA, 2004.
[24] J. Ellis, "Directed-Energy Weapons: Promise and Prospects", Center for a New American Security, USA, April 2015, Available: https://www.files.ethz.ch/isn/190363/CNAS_Directed_Energy_Weap ons_April-2015.pdf. 